\title{
Experience-Based Teaching Materials of Logic Circuits for Beginners
}

\author{
Takashi Miyagoshi Member (University of Toyama, miyagosi@eng.u-toyama.ac.jp) \\ Koji Okino Member (University of Toyama, okino@itc.u-toyama.ac.jp) \\ Masato Tajima Non-member (University of Toyama, tajima@eng.u-toyama.ac.jp)
}

Keywords : experience-based teaching material, logic circuits, NAND circuit, proper rearrangement

At extension lectures or open campus events whose participants are high school students or townspeople not always having any technical knowledge, it is necessary to prepare intuitive experience-based teaching materials.

The proposed teaching material is concerned with logic circuits.

Figure 1 shows the rough flow of the proposed system: first, on the screen where the menu is displayed, the students can choose one item from among random functions, functions represented in terms of a truth function, and basic logic programs.

For example, suppose that a 4-variable function has been generated in the form of a truth table. Then a corresponding logic tree made of permissible cubes is drawn based on the given function. Also, each permissible cube is transformed to a NAND gate and then a multi-level NAND circuit is generated using

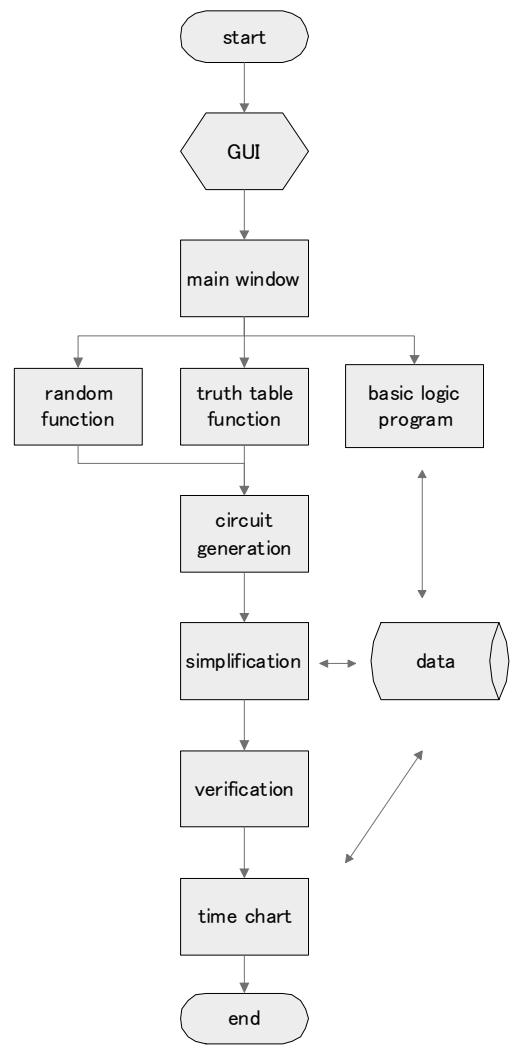

Fig. 1. Rough flow of the proposed system
NAND gates based on the prescribed connection information.

Finally, the resulting circuit is displayed on the screen.

Next, the obtained circuit is simplified by deleting redundant input lines and NAND gates, if necessary. Also, in the case of a highly complicated circuit due to duplicate connections between NAND gates, rearrangement of these NAND gates is performed.

Moreover, it is verified whether the obtained circuit is correctly corresponding to the given logic function. In the proposed system, when a basic logic program is selected, the input/output time charts for the basic logic elements (e.g., AND, OR, NOT) are displayed on the screen.

Figure 2 shows an example of multi-level NAND circuit generated based on a 4-variable logic function. Note that the terms "EXIT, ZOOM IN, ZOOM OUT, KENSYOU" are displayed on the upper part of the screen and the corresponding functions are available in the system.

Suppose that one clicks "KENSYOU". Then a small frame appears on the screen and you can verify the circuit in Fig.2 for the case that an input to the circuit is as specified in the frame. Every time one clicks, the contents in the frame change and accordingly all the cases (i.e., 0000 - 1111) can be verified.

The number of children has been decreasing and each university, which desires to secure enough students, tackles this issue earnestly. Hence, experience-based teaching materials such as mentioned above become more and more important at an open campus for high school students.

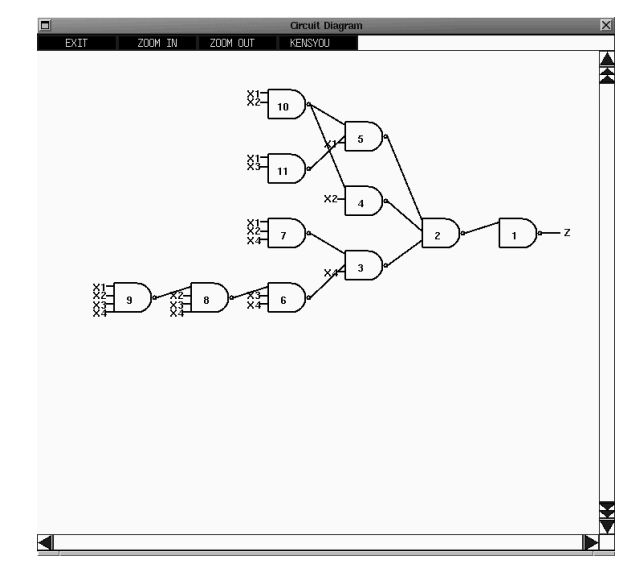

Fig. 2. An example of generated multi-level NAND circuit 


\title{
初心者のための論理回路体験教材システムについて
}

\author{
正員 宮腰隆* 正員 沖野 浩二** \\ 非会員 田島 正登*
}

\section{Experience-Based Teaching Materials of Logic Circuits for Beginners \\ Takashi Miyagoshi*, Member, Koji Okino**, Member, Masato Tajima*, Non-member}

\begin{abstract}
At an open campus, it is necessary to prepare intuitive experience-based teaching materials for high school students without technical knowledge. In this teaching material, which is based on an algorithm derived from the MA method (i.e., the method of (1)), the students can sequentially experience the following functions by the X-window of UNIX ; multi-level NAND circuit generation, simplification of the initially constructed circuit, proper rearrangement of circuit elements, verification of the obtained circuit, time-chart display, etc.
\end{abstract}

キーワード : 論理回路, 体験教材, NAND 回路, 適性配置

Keywords : logic circuits, experience-based teaching material, NAND circuit, proper rearrangement

\section{1. まえがき}

近年，少子化の影響もあり大学入学者数を確保するため に, 各大学とも高校生を対象とした大学見学会（オープン キャンパス) に力を入れている。2002 年度の実施校は $95.7 \%$ にも達している。その他, 中学生の公開講座やシニア向け の生涯教育講座などが企画され，学外の人に教育・研究内 容を紹介し, 体験してもらう機会が増えている。その際, 対象者は専門知識が皆無のため，わかりやすく簡単に体験 できることが重要となる。論理回路に関する CAD やアプリ ケーションはその高い専門性のため, 初心者が体験するに は不向きであると考えられるが, 著者らは(1)メニュー形式 による段階的な展開, (2)直観的でシンプルな操作性, など を考慮した教材システムを作成した。

本教材では，論理回路のいくつかの事項一与えた論理関 数から多段 NAND ゲート回路が自動的に生成される過程 ${ }^{(2)}$ やその描画，生成回路の簡単化，NAND ゲートの間隔を拡 げて見やすくする適正配置, 検証, タイムチャート表示 ${ }^{(3)(4)}$ など一が，順次わかりやすく体験できる。

本稿では，実行例により教材を説明し併せて課題につい ても検討した。

\footnotetext{
* 富山大学工学部知能情報工学科

干930-8555 富山市五福 3190

Dept. of Intellectual Information Systems Engineering, Faculty of Engineering, University of Toyama 3190 Gofuku, Toyama 930-8555

** 富山大学総合情報基盤センター

干930-8555 富山市五福 3190

Information Technology Center, University of Toyama.

3190 Gofuku, Toyama 930-8555
}

\section{2. 本教材について}

〈2・1〉構成および内容本教材のおおまかな構成と その実行手順を Fig. 1 に示す。

初心者を念頭においた本教材では, 論理回路の基礎的事 項をわかりやすく順を追って体験できる。

GUI (graphical user interface) である UNIX の X-Window ${ }^{(5)}$ を利用し, MA 法（文献(1)の方法）の考えをもとに導いた アルゴリズムにより，与えた論理関数から自動的に多段

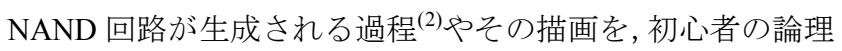
回路学習に役立つように加工した。

本教材の主な内容としては,

( i ) 3-16変数論理関数による多段 NAND回路の生成と 描画。

(ii）生成した回路から咒長なゲートと入力線を除去す る簡単化。

(iii) NAND ゲート間の接続がこみ入った回路では, 見や すくするために NAND ゲートの間隔を拡げる適性配 置。

(iv) 生成回路が与えられた関数を正確に実現している かどうかを調べる検証。

（v） 入出力関係が視覚的に確認できるタイムチャート 表示。

その他に,

（vi）各種基本論理素子（AND,OR,NOT など）の学習や7 セグメントLEDの表示。

などである。 


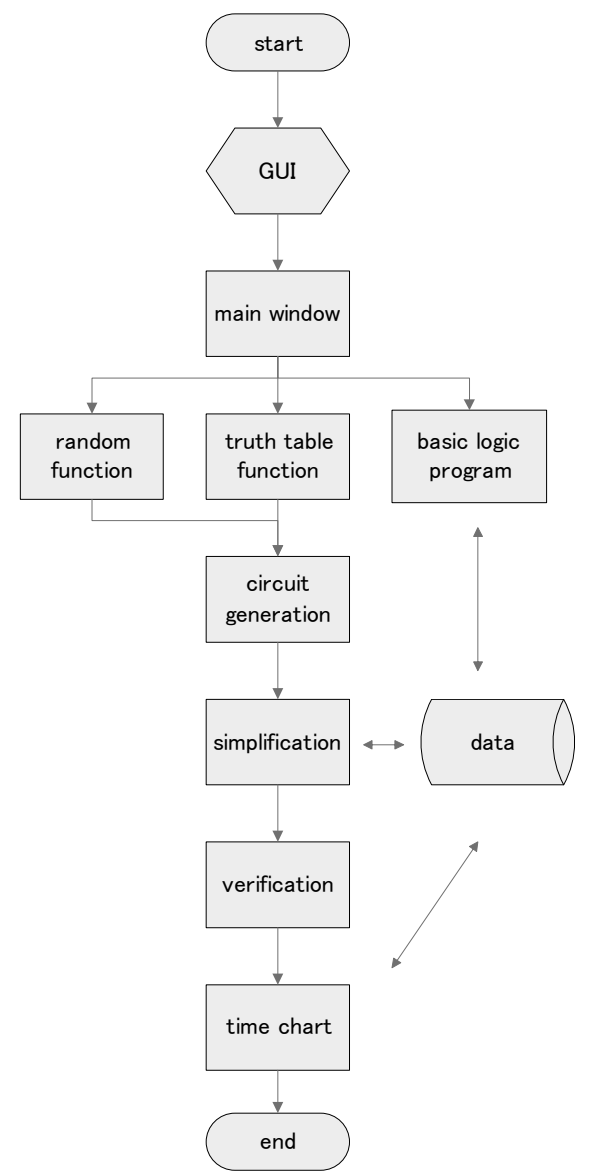

Fig. 1. Rough flow of the proposed system.

なお，実行プログラムは C 言語で作成した。

$\langle 2 \cdot 2\rangle$ 各部の実行例 便宜上, 4 変数関数の簡単な例 で説明する。

先ず, $\mathrm{tcl} / \mathrm{tk}^{(6)}$ というツールを用いた初期メニュー画面（選 択画面）でマウス操作によりモードを選ぶ。（ここでは中央 の “任意 NAND 回路表示”のスタートボタンをクリックす る (Fig. 2 参照) )。

Fig. 2 の上方の “ランダム NAND 回路表示”を選ぶと, 乱数を用いたランダム関数が発生できる。また, 下方の “論 理回路学習プログラム”では，各種基本論理素子および 7 セグメント LED について学習できる (Fig. 1 の main window 下の横方向 3 つに対応)。

続いて, 変数入力画面に変わるので 4 変数に設定する。 この場合は任意関数を真理值表形式で発生できる。ここで, $\mathrm{X}_{1}, \mathrm{X}_{2}, \mathrm{X}_{3}, \mathrm{X}_{4}$ は，それぞれ入力変数を $\mathrm{Z}$ は関数を表す。 例えば, 4 変数の真理值表形式で，1 にしたい箇所のみをク リック寸れば，その他は 0 である関数 Z が発生できる（Fig. 3)。

次に, Fig. 3 の関数に多段 NAND 回路生成法を適用する と肯定変数だけの積で表される許容項の木が生成される (Fig. 4)。Fig. 4 での許容項 $\mathrm{P}_{\mathrm{i}}$ の $\mathrm{i}$ は, 許容項の生成順番を表 し, その下の（）内の変数の積は, 許容項を構成する変 数である。ただし，適用した方法は NAND ゲートのみによ る回路構成のため, 出力ゲート $\left(\mathrm{P}_{1}\right)$ を付加するので $\mathrm{P}_{2}$ から始

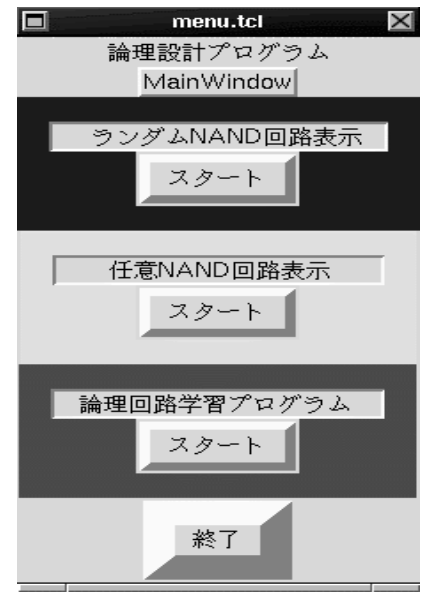

Fig. 2. Menu window.

$\begin{array}{lllll}\text { X1 } & \text { X2 } & \text { X3 } & \text { X4 } & \text { Z } \\ 0 & 0 & 0 & 0 & 1 \\ 0 & 0 & 0 & 1 & 0 \\ 0 & 0 & 1 & 0 & 1 \\ 0 & 0 & 1 & 1 & 1 \\ 0 & 1 & 0 & 0 & 0 \\ 0 & 1 & 0 & 1 & 0 \\ 0 & 1 & 1 & 0 & 1 \\ 0 & 1 & 1 & 1 & 0 \\ 1 & 0 & 0 & 0 & 0 \\ 1 & 0 & 0 & 1 & 0 \\ 1 & 0 & 1 & 0 & 1 \\ 1 & 0 & 1 & 1 & 1 \\ 1 & 1 & 0 & 0 & 1 \\ 1 & 1 & 0 & 1 & 1 \\ 1 & 1 & 1 & 0 & 1 \\ 1 & 1 & 1 & 1 & 1\end{array}$

Fig. 3. An example of 4-variable function.

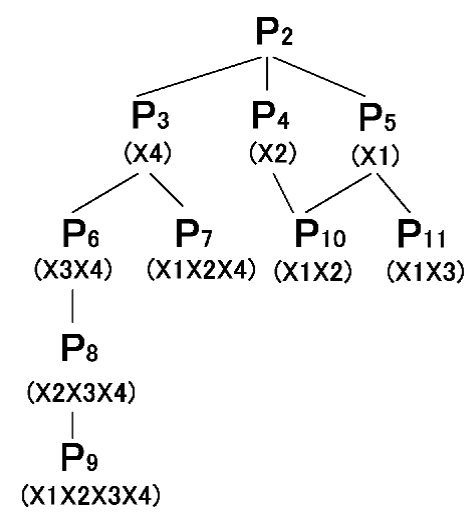

Fig. 4. A tree of permissible cubes.

まる。

この許容項の生成木において，各許容項をそれぞれ NAND ゲートに変換し, 併せて許容項を構成する変数を該 当 NAND ゲートの入力変数線とする。他方, これらの NAND ゲートの接続情報および入力变数線の情報を回路データと して保存しておく（Fig. 5)。Fig. 5 において，例えば上から 2 行目は, Gate 2 には Gate3，4，5 がつながっている。また， 


$\begin{array}{ll}\text { Gate } 1 & \text { Connect=2 } \\ \text { Gate 2 } & \text { Connect=3,4,5 } \\ \text { Gate 3 } & \text { Connect=6,7 } \\ \text { Gate } 4 & \text { Connect=10 } \\ \text { Gate 5 } & \text { Connect=10,11 } \\ \text { Gate 6 } & \text { Connect=8 } \\ \text { Gate 7 } & \text { Connect=0 } \\ \text { Gate } 8 & \text { Connect=9 } \\ \text { Gate 9 } & \text { Connect=0 } \\ \text { Gate10 } & \text { Connect=0 } \\ \text { Gate11 } & \text { Connect=0 } \\ \text { :::::::::::::::::::::::::::::::::::::::::::- } \\ & \\ \text { Gate 1 } & \text { Cube=11-X2-X3-X4 } \\ \text { Gate 2 } & \text { Cube=11-11-11-11 } \\ \text { Gate 3 } & \text { Cube=11-11-11-01 } \\ \text { Gate 4 } & \text { Cube=11-01-11-11 } \\ \text { Gate 5 } & \text { Cube=01-11-11-11 } \\ \text { Gate 6 } & \text { Cube=11-11-01-01 } \\ \text { Gate 7 } & \text { Cube=01-01-11-01 } \\ \text { Gate 8 } & \text { Cube=11-01-01-01 } \\ \text { Gate 9 } & \text { Cube=01-01-01-01 } \\ \text { Gate10 } & \text { Cube=01-01-11-11 } \\ \text { Gate11 } & \text { Cube=01-11-01-11 }\end{array}$

Fig. 5. Prescribed connection information.

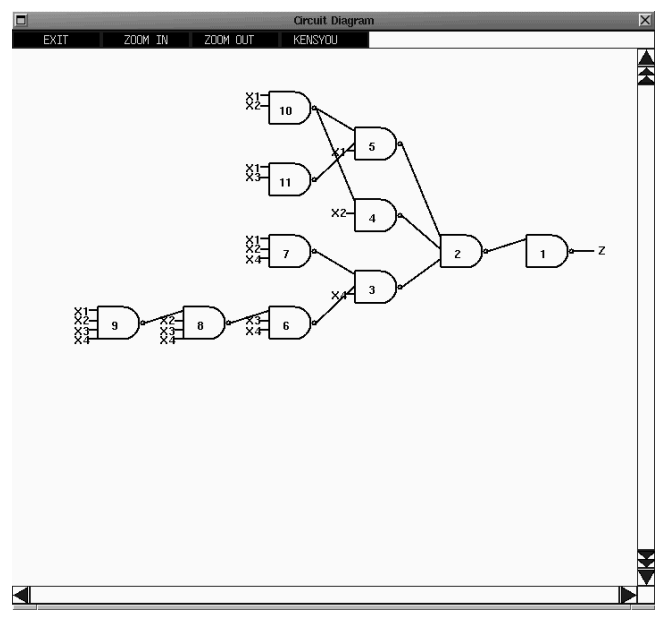

Fig. 6. A generated circuit from function in Fig.3.

同図下段の Gate 3 は許容項 $\mathrm{P}_{3}\left(\mathrm{X}_{4}\right)$ なので，変数 $\mathrm{X}_{4}$ を 0 と 1 の 2 ビットで 01 と表現している。同様に任意変数を 11 で, 否定変数を 10 と表す。

これらの回路データから回路描画を実行すると, Fig. 6 の 回路図が得られる。通常, 生成した（初期）回路は圥長な ため, 入力変数線やNAND ゲートの削減を図り回路を簡単 にする。Fig. 6 の関数例の場合は, これ以上簡単にならない。 また, Fig. 6 の上部黒側帯には, EXIT, ZOOM IN, ZOOM OUT，KENSYOU が用意してあり，クリックすればそれぞ れ「終了」,「拡大」,「縮小」,「検証」機能が働く。例えば, 今「KENSYOU」をクリックした場合, 入力変数が表示され る新たな小画面が現れ，クリックするごとに 0000 から 1111 まで変化し, Fig. 3 の各入力変数に対する関数 Z が所望の 0 または 1 になっているかどうかを確認することができる。

Fig. 7 は, 一組の入力変数 $\left(\mathrm{X}_{1} \mathrm{X}_{2} \mathrm{X}_{3} \mathrm{X}_{4}=0111\right)$ に対して,

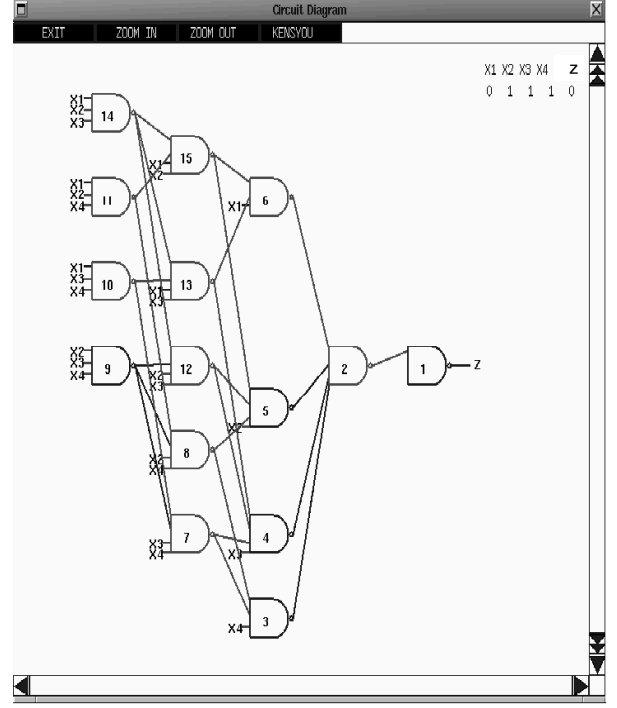

Fig. 7 .An example of verification.

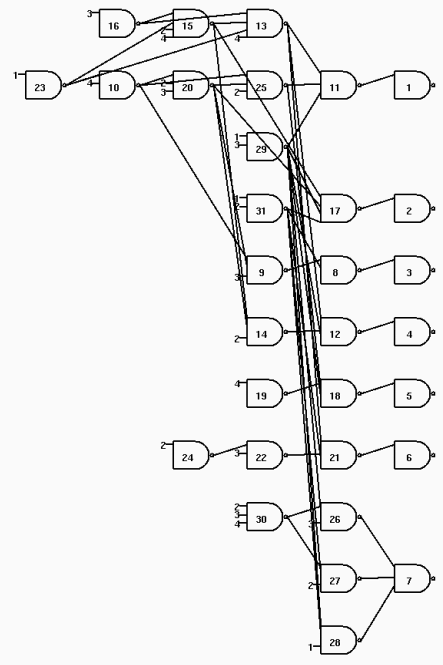

(a) Before

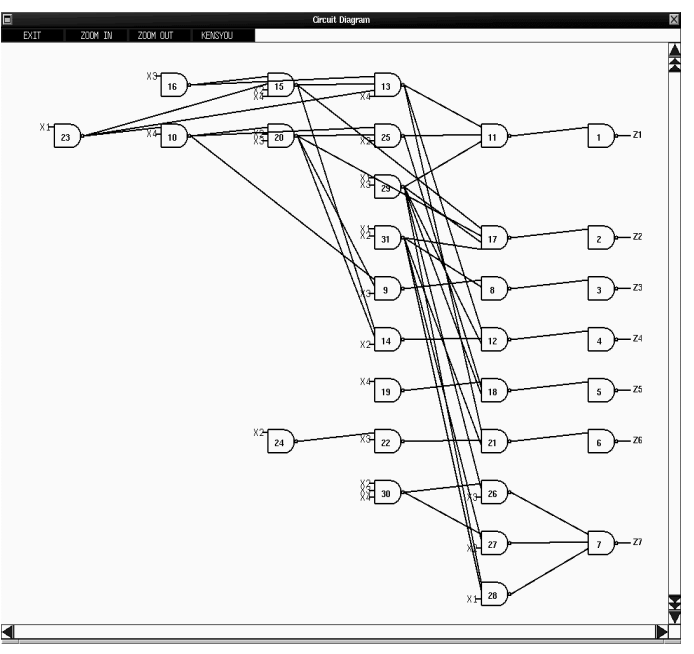

(b) After

Fig. 8. Proper rearrangement of NAND gates in 7 segment LED. 
入力端から出力端まで真（1）ならば赤色で, 偽（0）なら ば青色で表示され, 関数 Z が為（0）なので青色表示された 一例である。

本回路描画は，1 画面しか表示できないため，画面からは み出た箇所とか NAND ゲート間の接続線が重なって錯綜し ている部分などは，関係の把握が難しい。このため，新た に適正配置機能を追加した。

これは表示回路の NAND ゲート間の間隔を広く設定し て，見やすくする機能である。主な改良点は，

（1） NAND ゲート間の接続線交差数が一定数を越えた 時に，NAND ゲートの位置決め時に Y 座標の間隔を 広く取る。

(2) 連動してX座標の間隔も少し拡げる。

7 セグメント LED 表示回路のシミュレーション結果を例 とする (Fig. 8 参照)。(a)図の適性配置前では，NAND ゲー 卜間の接続線がこみ入って結合関係が分りにくかったが, (b)図の適性配置後では，見や寸く改善されている。

\section{3. むすび}

本教材は, 論理回路について知識のない人達もしくは初 心者を対象としているので，常時画面上に諸機能を表示し ておき必要に応じて使用できるようにした。また，回路を 2 色（真（1）ならば赤色, 偽（0）ならば青色）表示するこ とで，識別が容易で理解しやすくした。

今後, 入学者の減少傾向とともに大学の選別化が顕著に なってくることが予想されるので，高校生などが興味をも つわかりやすい体験型教材の開発や創作がますます必要か つ重要になってくる。

本教材を見学会で試行したところ，多数の高校生が興味 を示し，体験した。今後アンケートを実施しながら結果を 分析し, 本教材の操作性を向上させ, 合わせて一層の内容 の充実を図っていく所存である。

(平成 18 年 9 月 4 日受付，平成 19 年 1 月 12 日再受付)

\section{文献}

（1）松田秀雄・宮腰 隆：「論理式を分離加法形式で表現する一手法」, 情報処理学論, Vol.33, No.4, pp.560-569 (1992-4)
(2) 松田秀雄・宮腰 隆・畠山豊正:「多段 NAND ゲート回路の一設計 法」, 情報処理学会研究報告設計自動化, DA-67, pp.39-46 (1993-6)

( 3 ) T. Miyagoshi and H. Matsuda : "A tool for learning basic logic circuits", $T$. IEE Japan, Vol.121-A, No.7, pp.708-709 (2001-7) (in Japanese) 宮腰 隆・松田秀雄: 「基礎論理回路用補助教材」, 電学論 $\mathrm{A}, \mathbf{1 2 1}, 7$, pp.708-709 (2001-7)

(4) T. Miyagoshi and H. Matsuda : "An algorithm generating multi-level NAND logic circuits", T. IEE Japan, Vol.121-A, No.10, pp.962-963 (2001-10) (in Japanese)

宮腰 隆・松田秀雄: 「多段 NAND 論理回路の生成」, 電学論 A, 121, 10, pp.962-963 (2001-10)

（5）木下凌一・林 秀幸：X-Window Ver. II プログラミング， 日刊工業新 聞社 (1993)

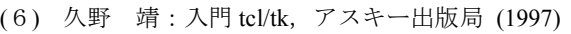

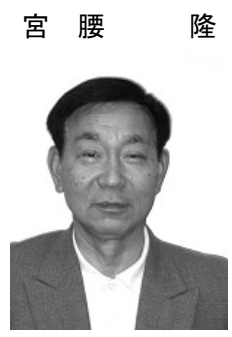

（正員） 1947 年 1 月 25 日生まれ。1972 年 3 月富山大学大学院工学研究科電気工学専攻修 士課程修了。現在, 富山大学工学部知能情報工 学科講師。博士 (工学)。主として教育工学, 論理回路設計に関寸る研究に従事。電子情報通 信学会, IEEE 会員。

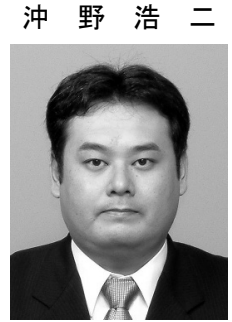

(正員） 1976 年 1 月 8 日生まれ。2000 年 3 月 富山大学大学院修士課程修了。現在, 富山大学 総合情報基盤センター助手および富山大学大 学院理工学研究科博士後期課程に在学中。セン サネットワーク, セキュリテイ関係の研究に従 事。電子情報通信学会会員。

田 島 正 登 （非正員） 1949 年 8 月 13 日生まれ。1979 年 3

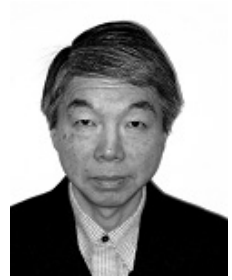
月早稲田大学大学院理工学研究科電気工学専 攻博士課程修了。現在, 富山大学工学部知能情 報工学科教授。工学博士。主として符号理論に 関する研究に従事。電子情報通信学会, IEEE 会員。 